Western University Scholarship@Western

Aboriginal Policy Research Consortium International (APRCi)

2001

\title{
Inhalant Use by Canadian Aboriginal Youth
}

Heather Coleman

Grant Charles

Jennifer Collins

Follow this and additional works at: https://ir.lib.uwo.ca/aprci

Part of the Substance Abuse and Addiction Commons

Citation of this paper:

Coleman, Heather; Charles, Grant; and Collins, Jennifer, "Inhalant Use by Canadian Aboriginal Youth" (2001). Aboriginal Policy Research Consortium International (APRCi). 279.

https://ir.lib.uwo.ca/aprci/279 
This article was downloaded by: [University of Western Ontario]

On: 16 December 2012, At: 07:34

Publisher: Routledge

Informa Ltd Registered in England and Wales Registered Number: 1072954 Registered office: Mortimer House, 37-41 Mortimer Street, London W1T 3J H, UK

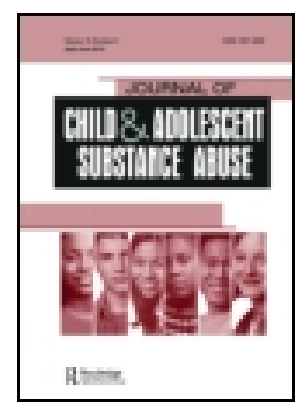

\section{J ournal of Child \& Adolescent Substance Abuse}

Publication details, including instructions for authors and subscription information:

http:// www.tandfonline.com/loi/ wcas20

\section{Inhalant Use by Canadian Aboriginal Youth}

Heather Coleman, Grant Charles \& J ennifer Collins

Version of record first published: 22 Oct 2008.

To cite this article: Heather Coleman, Grant Charles \& J ennifer Collins (2001): Inhalant Use by Canadian Aboriginal Youth, J ournal of Child \& Adolescent Substance Abuse, 10:3, 1-20

To link to this article: http:// dx.doi.org/10.1300//029v10n03_01

\section{PLEASE SCROLL DOWN FOR ARTICLE}

Full terms and conditions of use: http://www.tandfonline.com/page/terms-and-conditions

This article may be used for research, teaching, and private study purposes. Any substantial or systematic reproduction, redistribution, reselling, loan, sub-licensing, systematic supply, or distribution in any form to anyone is expressly forbidden.

The publisher does not give any warranty express or implied or make any representation that the contents will be complete or accurate or up to date. The accuracy of any instructions, formulae, and drug doses should be independently verified with primary sources. The publisher shall not be liable for any loss, actions, claims, proceedings, demand, or costs or damages whatsoever or howsoever caused arising directly or indirectly in connection with or arising out of the use of this material. 


\title{
Inhalant Use by Canadian Aboriginal Youth
}

\author{
Heather Coleman \\ Grant Charles \\ Jennifer Collins
}

\begin{abstract}
While inhalant abuse is a significant problem among Canada's Aboriginal (indigenous) people, it is poorly understood. This study was conducted in response to these issues. The authors followed 78 Aboriginal young people who received treatment for inhalant abuse in a program established by the federal government. Data were based on a secondary analysis of case files as well as follow-up information from community workers.

Seventy-four percent of the 78 young people tracked during followup relapsed after discharge from treatment. Many of the young people came from backgrounds marked by isolation, poverty, family violence and substance abuse. The average age these young people started using solvents was 9.72 years. Gasoline was the most common inhalant used. Inhalant use was often accompanied by alcohol and drug abuse. A logistic regression model predicting who would relapse indicated that young people who abused inhalants immediately before admission, those who were described as unmotivated in treatment and those who were hospitalized during treatment had the greatest risk of relapsing during follow-up. Implications are discussed. [Article copies available for a fee from The Haworth Document Delivery Service: 1-800-342-9678. E-mail address: <getinfo@haworthpressinc.com> Website: <http://www.HaworthPress. com> (C) 2001 by The Haworth Press, Inc. All rights reserved.]
\end{abstract}

KEYWORDS. Inhalant abuse, predictors of relapse, Aboriginal young people

Substance abuse in Aboriginal communities negatively affects the social, economic, health and spiritual well-being of Aboriginal peoples (Beauvais, 1992; Johnson, 1994; Mail \& Johnson, 1993; Sage \&

Journal of Child \& Adolescent Substance Abuse, Vol. 10(3) 2001

(C) 2001 by The Haworth Press, Inc. All rights reserved. 
Burns, 1994). (In this paper, the term "Aboriginal" in this study refers to Canada's indigenous people.) Substance abuse can begin at young ages and understanding young people's use of substances can shed light on evolving patterns of later use (Kandal \& Logan, 1984; Yamaguchi \& Kandel, 1984). Marijuana, inhalants and stimulants are all used at higher rates by Aboriginal youth than other young people. The highest risk period for initiation to substances falls between the ages of ten and thirteen. For pre-teens, the use of inhalants seems to play a role in an unfolding pattern of drug involvement. The average age for first using inhalants among Aboriginal children is approximately 11.5 years (Beauvais \& Segal, 1992). Another study reported the average age for first use as 13.1 for antisocial youth (Howard \& Jenson, 1999).

While inhalant abuse is not a new problem (Sharpe, 1992), it has only been the subject of serious investigation over the past twenty years (Castiglia, 1993). Factors associated with inhalant abuse have not been fully investigated and are therefore poorly understood. In addition, many inhalant abusers are often members of marginalized groups (Sharpe, 1992), making them difficult to study.

Inhalant abuse in Canada is found across cultural groups, as is the case elsewhere. However, in Canada much of the abuse appears to be concentrated in Aboriginal communities where rates of use are higher for males (Innes \& Charles, 1996; Smart, 1997; Zebrowski \& Gregory, 1996). Usage is higher in isolated communities and in communities that also experience high rates of unemployment, poverty, and violence. That is, the lowest rate of inhalant abuse occurs in communities with high social assets. Howard and Jenson (1999) also found that inhalant users reported less family support and cohesiveness, low self-esteem, more thoughts of suicide and substance-abusing parents and peers. Others suggest that socioeconomic conditions, lack of family cohesiveness and strength, peer influence, poor school adjustment and the extent of acculturation are factors for Aboriginal young people (Beauvais \& LaBoueff, 1985; Severson, 1984).

Anecdotal information from Aboriginal communities across the country suggests that community denial of the extent of the problem in communities is pervasive. While the denial has decreased over recent years, it appears that inhalant abuse is seldom openly discussed or considered a problem. Often, the behaviors are ignored or normalized. Minimization of the problem may be due to a number of factors. 
Community members might be afraid of inhalant abusers and their unpredictable behaviors. Others find the issue overwhelming and hope that it will disappear. Ignoring the problem may also be easier because many inhalant abusers are marginalized within their home communities. For example, one elder described inhalant users as "bats" that only came out at night (Charles \& Coleman, in press). Whatever the reason, inhalant abuse has not received the necessary attention until recently. Unfortunately, it continues to destroy the lives of many Aboriginal youth.

In response to national Canadian concern about inhalant use among Aboriginal young people throughout Canada, a residential treatment program for Aboriginal youth, known as the National Breakthrough Inhalant Program, was established. The program was operated as part of a larger continuum of services at Woods Homes in Calgary, Alberta. While the program served adolescents between the ages of twelve and nineteen, younger children were also served in exceptional circumstances.

The Medical Services Branch, Health Canada funded the program, between 1993 and 1997. The program provided intensive residential treatment until Aboriginal communities established their own treatment facilities. By early 1997, programs had opened in six Aboriginal communities across Canada, leading to the closure of the National Breakthrough Program.

The program assisted young people to break the cycle of inhalant abuse experienced by themselves, their families and their communities. It encouraged the youth to face inhalant use, "mastering it" and transferring the skills learned in treatment back to home communities. A wellness and cultural healing model was implemented within the program to support and encourage young people and their families find alternative ways of dealing with emotional pain, stress, family conflict and feelings of hopelessness. Each young person's treatment experience was tailored towards his/her unique needs. Mutually agreed upon goals were developed in partnership with the young person and family, when possible. Families often lived long distances from the program but family involvement was encouraged through family visits to the program. When families did visit the program, they participated in the treatment and counseling process.

Young people typically entered the program through a residential setting. When a young person first entered the program, 24-hour de- 
toxification period and nursing/medical services were provided. In the later stages of treatment, young people had the opportunity to move into a caregiver setting prior to returning to their home communities. Caregiver homes were located both within Calgary and on nearby reserves. The residential phase of the program usually lasted six to nine months.

A variety of professionals and people were involved in the program. Front-line staff provided daily interventions to address the young person's goals. They also offered the structure and nurturance. Each young person was matched with a front-line staff who became their "coach." The "coach" played a central role in managing the young person's treatment. Clinicians and a consulting psychiatrist were involved in providing therapeutic services to the young people and their families. Consulting physicians and program nurses provided medical services. Schoolteachers also provided educational services. Elders participated in and guided the cultural healing component of the program. Cultural events and healing ceremonies were an integral part of treatment.

The program was structured around the Medicine Wheel, with the four phases of treatment relating to the four seasons of the year. Young people moved through the four phases during their time in treatment, with each season representing a stage in the healing process. Each phase also included specific goals and tasks developed with the young people as part of their overall treatment plans.

"Spring" was symbolized by a time of new beginnings for each individual. It involved learning to relinquish health-compromising behaviors and envisioning a health-enhancing lifestyle. The "summer" represented a time of self-expression and self-honesty to promote healing. During "fall," the young person learned to be kind to themselves and others, identify triggers for inhalant use, and develop relapse prevention strategies. The final phase, "winter," focused on practicing relapse skills and health-enhancing choices. They also assumed leadership roles within the program and shared knowledge, through role modeling and verbal communication. Focus was given to how the young people could transfer skills and health-enhancing lifestyles to home communities and families.

The treatment program combined Aboriginal and non-Aboriginal approaches to healing. Individual, family and group therapy was conducted on a regular basis within the context of a healing circle concept 
by professional staff working in conjunction with Elders and other aboriginal teachers. The young people regularly participated in traditional ceremonies. The young people also attended school and took part in community activities. They had access to psychiatric and other specialized medical services on an as-needed basis. The young people and their families also had access to the full range of clinical services operated by Woods Homes.

The primary treatment goals for these young people involved decreasing inhalant abuse, identifying triggers for inhalant abuse, teaching relapse strategies and helping to find alternatives to inhalant abuse. Others included emotional awareness and expression, education, relationship skills, and boundary work. Dealing with family issues figured prominently as a treatment goal. However, because of the distance from the young people's home communities, family work was not always possible.

Discharge planning occurred with all available people closely involved in a young person's life. This included families, parents, social service and child welfare agencies, program and consulting staff and home community resources. The program also provided consultation, training and community development services to aboriginal communities across the country in order to assist them to develop strategies to break the cycle of inhalant abuse. A team of professionals traveled to communities to provide after-care services to the young people who had been in the program.

This exploratory study was designed to address two questions:

1. What is the profile of the youth who received treatment from the National Breakthrough Inhalant Abuse Program?

2. What set of variables from case files best predict inhalant abuse after discharge from the National Breakthrough Inhalant Abuse Program?

This was a retrospective study, based on secondary analysis of data from case files. Limitations applicable to these two approaches are relevant here, including reliability of coding, and the use of data not designed particularly for the purposes of this study. As such, there were missing data for some of the variables used in this study. However, given the exploratory nature of the study and the usefulness of the information, even with missing data, we decided to proceed with data analysis. Because of missing data, tables do not always add up to one 
hundred percent. In the multivariate logistic regression model only variables were used that had adequate data.

Follow-up information was based on the recall of the follow-up workers. In addition, this study does not suggest that the predictor variables relapse. It should be mentioned that there is a paucity of research or theoretical literature about inhalant abuse. This study is one of the largest available in terms of sample size and amount of data pertaining to follow-up information and relapse. It provides a rich base from which to start to understand inhalant abuse.

\section{METHOD}

A secondary analysis of treatment files from the National Breakthrough Inhalant Program was conducted. Data included basic demographic information, a description of substance abuse problems, medical information, family background, and treatment information. Additionally, one of the researchers met with follow-up workers from home communities to obtain information about what happened to the youth after discharge from treatment. File information was used to develop a prediction model for relapse during follow-up.

The follow-up information was collected by aftercare workers from the treatment team as part of their regular duties. The information was gathered from a variety of sources. In some cases, the information came from family members or guardians. In other cases, the information was collected from band council members, health care workers, members of the local police force or other professionals. In each instance, the information was gathered through face to face discussion or through telephone contact.

\section{Data Analysis}

This study sought to find which factors (predictor variables) best predicted relapse to inhalant abuse during follow-up. Relapse was determined by reports of follow-up workers. Follow-up workers lived in the home communities of the young people. Logistic regression can be used to find the best combination of independent variables that influenced the probability of a youth relapsing to inhalant use during the follow-up period. Logistic regression is a statistic that can be used 
when the dependent variable is discrete, that is, having only two values. In this study, the two values of the dependent variable were "relapsed" and "did not relapse." Logistic regression emphasizes the probability of a particular outcome for each case (Tabachnick \& Fidell, 1996). For example, logistic regression can evaluate the probability that a given young person in this sample will relapse, given his or her values on each variable (predictor variable).

Data analysis was done in SPSS for Windows, which uses Model Chi-square and $\square 2$ Log Likelihood to test the fit of the model. Model Chi-square and $\square$ R Log Likelihood are statistics that show how well the data fit the model.

\section{RESULTS}

\section{Sample}

Subjects included 78 young people who received treatment in the National Breakthrough Inhalant Abuse Program at a Treatment Center in Western Canada over two and one-half years. Thirty-one cases were excluded from the analysis because of incomplete follow-up information about relapse. The age range of the young people during treatment was from seven to nineteen. The follow-up period occurred approximately two years after discharge from the program. Of the youth, 21 were female and 57 were male. Average age at admission to the program was $14.36(\mathrm{SD}=2.09)$ and $16.60(\mathrm{SD}=2.20)$ at follow-up.

All were admitted with the presenting problem of inhalant abuse; 70 percent were concurrently abusing other drugs and 29 percent of the youth had abused alcohol. Youth in this study experienced numerous other difficulties, including a history of physical abuse (52.7 percent), a history of sexual abuse (43.6 percent), aggressive and violent behavior (44.5 percent), suicide attempts and concerns (40.4 percent) and low self-esteem (45.5 percent). Other presenting problems are shown in Table 1.

The average length of time spent in treatment was 176.40 days $(\mathrm{SD}=93.18)$ and ranged from 7 to 423 days. All of the young people were Status Indian, meaning that their band had signed a treaty with the Canadian federal government. The most common referral source was child welfare (29.4 percent), followed by the National Native Alcohol and Drug Abuse Program (NNADAP) (22.0 percent). 
TABLE 1. Environmental Factors

\begin{tabular}{|c|c|c|c|c|}
\hline & \multicolumn{2}{|c|}{$\underline{\text { Yes }}$} & \multicolumn{2}{|c|}{$\underline{\text { No }}$} \\
\hline & $\mathrm{N}$ & Percent & $\mathrm{N}$ & Percent \\
\hline Poverty & 12 & 16.4 & 66 & 84.6 \\
\hline Family unemployment & 19 & 24.4 & 59 & 75.6 \\
\hline $\begin{array}{l}\text { Community geographical } \\
\text { isolation }\end{array}$ & 24 & 30.8 & 54 & 69.2 \\
\hline Lack of social/health services & 21 & 26.9 & 57 & 73.1 \\
\hline Severe winter conditions & 9 & 11.5 & 69 & 88.5 \\
\hline $\begin{array}{l}\text { High level of substance abuse } \\
\text { in the community }\end{array}$ & 26 & 33.3 & 52 & 66.7 \\
\hline $\begin{array}{l}\text { Recent deaths in family } \\
\text { accidental } \\
\text { suicide } \\
\text { murder } \\
\text { unknown reason }\end{array}$ & $\begin{array}{r}39 \\
10 \\
10 \\
6 \\
8\end{array}$ & $\begin{array}{r}50.0 \\
12.8 \\
12.8 \\
7.7 \\
10.3\end{array}$ & $\begin{array}{l}39 \\
68 \\
68 \\
72 \\
70\end{array}$ & $\begin{array}{l}50.0 \\
87.2 \\
87.2 \\
92.3 \\
89.7\end{array}$ \\
\hline $\begin{array}{l}\text { Historical deaths in family } \\
\text { accidental } \\
\text { suicide } \\
\text { murder } \\
\text { unknown reason }\end{array}$ & $\begin{array}{r}24 \\
7 \\
11 \\
4 \\
6\end{array}$ & $\begin{array}{r}30.8 \\
9.0 \\
14.1 \\
5.1 \\
7.7\end{array}$ & $\begin{array}{l}54 \\
71 \\
67 \\
74 \\
72\end{array}$ & $\begin{array}{l}69.2 \\
91.0 \\
85.9 \\
94.9 \\
92.3\end{array}$ \\
\hline Poor housing conditions & 13 & 16.7 & 65 & 83.3 \\
\hline Poor access to school & 13 & 16.7 & 65 & 83.3 \\
\hline Parents separated/divorced & 22 & 28.6 & 55 & 71.4 \\
\hline Mother deceased & 12 & 15.4 & 66 & 84.6 \\
\hline Father deceased & 5 & 6.4 & 73 & 93.6 \\
\hline Family violence & 28 & 35.9 & 49 & 62.8 \\
\hline Completed suicide in family & 21 & 26.9 & 57 & 73.1 \\
\hline Attempted suicide in family & 6 & 7.7 & 72 & 92.3 \\
\hline Parental suicide & 7 & 9.0 & 71 & 91.0 \\
\hline $\begin{array}{l}\text { Family alcohol/substance abuse } \\
\text { father } \\
\text { mother } \\
\text { siblings } \\
\text { extended }\end{array}$ & $\begin{array}{l}70 \\
56 \\
61 \\
25 \\
32\end{array}$ & $\begin{array}{l}89.7 \\
71.8 \\
78.2 \\
32.1 \\
41.0\end{array}$ & $\begin{array}{r}8 \\
22 \\
16 \\
53 \\
46\end{array}$ & $\begin{array}{l}10.3 \\
28.2 \\
20.5 \\
67.9 \\
59.0\end{array}$ \\
\hline $\begin{array}{l}\text { Family inhalant abuse } \\
\text { father } \\
\text { mother } \\
\text { siblings } \\
\text { extended }\end{array}$ & $\begin{array}{r}39 \\
5 \\
7 \\
34 \\
11\end{array}$ & $\begin{array}{r}50.0 \\
6.4 \\
9.0 \\
43.6 \\
14.1\end{array}$ & $\begin{array}{l}39 \\
73 \\
71 \\
44 \\
67\end{array}$ & $\begin{array}{l}50.0 \\
93.6 \\
91.0 \\
56.4 \\
85.9\end{array}$ \\
\hline
\end{tabular}

Note. The values in these categories were based on the self-report of the young person. Thus, some variables, such as poverty, are defined as "if the young person believed there was poverty when they were growing up." Poverty in this case does not refer to any standard social measure of poverty. 
Other referral sources included bands and drug and alcohol workers. Federal Medical Services was the predominant funding source.

Prior to admission, young people encountered many environmental and community hardships (Table 1). Half had experienced a recent death involving suicide, accidental death and murder. A death was deemed "recent" if it occurred within the past five years. Nearly one-third had experienced a death in the family historically. The definition of a "historical death" was a death that occurred more than five years prior to receiving treatment in the program. Community-related problems included geographical isolation (30.8 percent), lack of social and health services (26.9 percent), and high rates of substance abuse in home communities (33.3 percent). Some authors have reported that communities with high social risk factors increase the risk of inhalant abuse (Smart, 1997).

\section{Family Background}

The young people came from a variety of family structures, with close to forty percent coming from two-parent families. Fifteen biological mothers and eight biological fathers were deceased. Family violence was common in the backgrounds and slightly more than one third (36.4 percent) had experienced some form of family violence. Suicide and homicide were also quite prevalent in these families. Almost one quarter of all families had experienced a completed suicide and in 7.3 percent of all cases, the suicide involved a parent.

Notably, over 90 percent of all families experienced substance abuse involving at least one family member other than the identified youth. According to case files, 68 percent of fathers and 72 percent of mothers had abused alcohol. Far fewer parents had ever reportedly received treatment for substance abuse-only 12.8 percent of fathers and 18.3 percent of mothers. While inhalant abuse among parents was less common, it did occur in about 15 percent of the cases.

\section{Medical History}

In approximately forty percent of the cases, the prenatal history of the youth included a pregnancy where substances were abused (i.e., where the mother admitted to alcohol abuse). Most of the young people had an extensive history of medical difficulties while growing 
up. Approximately one-third (30.0 percent) had been involved in an accident during childhood. Almost two-thirds (62.7 percent) had experienced medical neglect and 59.6 percent had been hospitalized during. Half of the children were diagnosed with heart murmurs and approximately the same number (51.8 percent) had dental problems. In addition, thirty-nine ( 35.5 percent) children experienced neuropathy secondary to inhalant abuse. Hearing and vision difficulties were also widespread in this group. Twenty-one percent experienced the former and 34.5 percent the latter.

\section{Use of Chemicals}

A high number of young people were involved in chronic abuse of inhalants defined as daily use. Further, the age at which inhalant use was started was very young. The average age of first using inhalants was 9.72 years $(\mathrm{SD}=2.78)$. This age is considerably younger than the 11.5 years reported by Beauvais and Segal (1992) and the 13.1 reported by Howard and Jenson (1999). However, a report by Zebrowski and Gregory (1996), that heavy users are most likely to start between the ages of 9 and 11, gave reason for concern for the early age of starting within this group. Since these latter two studies are American, more research is needed to determine whether Aboriginal youth in Canada are starting inhalants earlier than their American counterparts. Approximately half started using inhalants between the ages of 6 and 10 , while nearly a third started between the ages of eleven and thirteen. Inhalants appeared to be the "gateway" drug for these young people.

Age for initiation to inhalant use ranged from four to sixteen. One half of all the young people had first tried inhalants by the age of ten and by age twelve, three-quarters had been initiated to inhalants.

Table 2 shows that the most common inhalant used was gasoline, a finding reported in other studies (Zebrowski \& Gregory, 1996). Ninetyone percent admitted to sniffing gasoline. One-quarter (25.6 percent) reported having sniffed nail polish and one-fifth had used whiteout. Other common inhalants included lacquer thinner, plastic wood and rubber cement. Most often, inhalants were used with friends (61.5 percent). Close to seventy percent experienced hallucinations with inhalant use and the most common form of hallucination was visual (44.9 percent). 
TABLE 2. Inhalant Abuse History $(\mathrm{N}=78)$

\begin{tabular}{|c|c|c|c|c|}
\hline & \multicolumn{2}{|c|}{ Yes } & \multicolumn{2}{|c|}{ No } \\
\hline & $\mathrm{N}$ & Percent & $\mathrm{N}$ & Percent \\
\hline \multicolumn{3}{|l|}{ Use of inhalants } & 30 & 38.5 \\
\hline \multicolumn{5}{|l|}{ Type of inhalant } \\
\hline paint thinner & 3 & 3.8 & & 87.2 \\
\hline spray paint & 4 & 5.1 & 67 & 85.9 \\
\hline lacquer thinner & 12 & 15.4 & 59 & 75.6 \\
\hline whiteout & 15 & 19.2 & 56 & 71.8 \\
\hline gasoline & 69 & 91.2 & 2 & 2.6 \\
\hline nail polish & 20 & 25.6 & 51 & 65.4 \\
\hline glue & 3 & 3.8 & 68 & 87.2 \\
\hline plastic wood & 10 & 12.8 & 61 & 78.2 \\
\hline hair spray & 6 & 7.7 & 65 & 83.3 \\
\hline bleach & 1 & 1.3 & 70 & 89.7 \\
\hline rubber cement & 9 & 11.5 & 62 & 79.5 \\
\hline markers & 4 & 5.1 & 67 & 85.9 \\
\hline camp fuel & 7 & 9.0 & 64 & 82.1 \\
\hline Lysol & 3 & 3.8 & 68 & 87.2 \\
\hline Taken alone & 30 & 38.5 & 20 & 25.6 \\
\hline Taken with friends & 48 & 61.5 & 6 & 11.1 \\
\hline Taken with alcohol & 19 & 24.4 & 24 & 30.8 \\
\hline Taken with drugs & 12 & 15.4 & 33 & 42.3 \\
\hline Hallucinations & 53 & 67.9 & 11 & 14.1 \\
\hline visual & 35 & 44.9 & 13 & 16.7 \\
\hline auditory & 11 & 14.1 & 37 & 47.4 \\
\hline
\end{tabular}

"Triggers" for inhalant abuse were usually associated with negative emotional states. The most common trigger was anger (25.6 percent), followed closely by boredom (24.4 percent), sadness (16.7 percent) and loneliness (14.1 percent). Other triggers included frustration, fear and nervousness. Similarly, Zebrowski and Gregory (1996) reported that affective states were often triggers for heavy users. For nearly one third (29.5 percent), peer influence was a reported factor in inhalant abuse. This compares with 55 percent reported in the study by Zebrowski and Gregory (1996). Close to one-fifth of the group was taught to abuse inhalants by friends.

Many of the young people in this study also used other chemicals, a finding found elsewhere (Smart, 1997). In this study, alcohol was used by 81.8 percent of the young people and for one-fifth of the sample, alcohol use was considered heavy. "Heavy use" reflected extensive 
inhalant use that may have resulted in noticeable signs of intoxication and hallucinations. Both beer and hard liquor were consumed about equally. Close to forty percent of these young people had consumed alcohol at least once a week before admission. Two-thirds (64.2 percent) of the young people also admitted to having used drugs. Marijuana was the most common drug used (48.2 percent), followed by hash (30.9 percent). Other drugs included skunkweed, cocaine and LSD.

The average age of first alcohol use was 11.5 ( $\mathrm{SD}=2.34$ ) with the age for initiation to alcohol ranging from ages five to fifteen. Alcohol use was followed by marijuana use $(\mathrm{M}=12.61, \mathrm{SD}=2.11)$ and hash $(\mathrm{M}=12.77, \mathrm{SD}=2.31)$. Unfortunately, data related to age of initiation to nicotine was not collected. However, eighty-seven percent of these young people were smokers, a percentage considerably higher than among Aboriginal adults in a national sample (Stevens, 1991).

\section{Treatment Information}

A number of behaviors were observed while the young person was in treatment. Most importantly, 86 went AWOL at some point during treatment during which time, staff observed that inhalant abuse often occurred during these absences. Over one-third (35.8 percent) expressed some suicidal ideation. Many were also verbally and physically aggressive while in treatment. Seventy percent demonstrated violent behavior while in the program. In addition, thirty-eight were considered by staff to be motivated and 38 were abstinent in treatment. "Motivation in treatment" was determined through staff observation of the young person's behavior and it was based on active participation in the different aspects of the treatment program. Compliance with daily expectations and cottage routines, engagement and participation in treatment groups and clinical sessions, and participation in cultural activities were criteria that reflected a young person's motivation in treatment

Youth were more likely to be hospitalized during treatment if they admitted to inhalant use immediately before admission to the treatment center, $\left.?^{2}(1, \mathrm{~N}=78)=9.38, p<.05\right)$. Additionally, young people who were abstinent while in treatment were less likely to be hospitalized during treatment, $\left.?^{2}(1, \mathrm{~N}=78)=6.77, p<.05\right)$. Only 11 of the young people who were abstinent during treatment were also hospitalized, compared with 35 young people who were not abstinent in treatment. Inhalant use immediately before admission was associated with absti- 
nence during treatment, $\left.?^{2}(1, \mathrm{~N}=78)=60.50, p<.05\right)$. Of the sixty-three people not abstinent in treatment, fifty-eight had used inhalants immediately before admission compared with thirty-one young people who were abstinent in treatment and did not use inhalants immediately prior to entering treatment.

\section{Follow-Up Information}

Eighty-six percent of all the young people returned to home communities with two-thirds discharged to the home of their parents. As demonstrated in Table 3, 51.4 percent reportedly used inhalants during follow-up, 22.9 percent used alcohol and 9.2 percent were involved with drugs. In addition, one-quarter had been involved in some criminal activity and two young people had completed suicide.

Follow-up inhalant use was significantly associated with hospitalization during treatment, $\left.?^{2}(1, \mathrm{~N}=78)=6.77, p<.05\right)$. That is, young people who relapsed to inhalant use during follow-up were more likely to have been hospitalized during treatment. Thirty-one young people who relapsed during follow-up had been hospitalized compared with only five who had not relapsed. Additionally, relapse was significantly associated with failure to remain abstinent during treatment, $\left.?^{2}(1, \mathrm{~N}=78)=5.62, p<.05\right)$ and not being motivated in treatment, $\left.?^{2}(1, \mathrm{~N}=78)=5.39, p<.05\right)$. In addition, having respiratory infections as a child was associated with relapse, $\left.?^{2}(1, \mathrm{~N}=78)=3.33, p<.05\right)$.

TABLE 3. Follow-Up Information

\begin{tabular}{lrrrr}
\hline & $\mathrm{N}$ & Yes & & No \\
& 11 & 16.7 & 55 & 83.3 \\
Early discharge & 56 & 71.8 & 22 & 28.2 \\
Used inhalants & 24 & 50.0 & 24 & 50.0 \\
Used alcohol & 7 & 17.9 & 32 & 41.0 \\
Used drugs & 25 & 26.6 & 56 & 71.8 \\
Criminal activity & 22 & 20.2 & 28 & 52.8 \\
Incarceration & 20 & 24.7 & 56 & 71.8 \\
Received further treatment & 70 & 89.7 & 3 & 4.1 \\
Went home to community & & & & \\
\hline
\end{tabular}


Possibly, respiratory infections were symptomatic of respiratory damage aggravated or caused by inhalants and acted as a proxy variable for chronicity of inhalant abuse.

\section{Predictors of Relapse}

\section{Bivariate Findings}

As shown in Table 4, twelve bivariate coefficients significantly related to relapse during follow-up. The sign of the relationship between each coefficient and the outcome highlights the direction of the relationship. Thus, predictors such as motivation for treatment and having family support in place decreased the likelihood that the young person would relapse during follow-up. Conversely, predictors such as maternal substance abuse, hospitalization during treatment, using inhalants during treatment and drug abuse as a presenting problem increased the likelihood that the young person would relapse during

TABLE 4. Variables that Successfully Predicted Inhalant Abuse at Follow-Up

\begin{tabular}{|c|c|c|c|c|c|c|}
\hline Variable & $\square$ & S.E. & Wald & $\underline{\mathrm{p}}$ & $\operatorname{Exp}(\square)$ & $\begin{array}{l}\text { Odds } \\
\text { Ratio }\end{array}$ \\
\hline $\begin{array}{l}\text { Not abstinent during } \\
\text { treatment }\end{array}$ & .6464 & .2796 & 5.3132 & .02 & 5249 & 1.42 \\
\hline Current inhalant use & .7252 & .2667 & 7.3933 & .007 & 2.065 & 4.87 \\
\hline $\begin{array}{l}\text { Drug use as presenting } \\
\text { problem }\end{array}$ & .6708 & .3350 & 4.0104 & .05 & 1.956 & 3.19 \\
\hline Family support in place & $\square 1.0237$ & .5080 & 4.0613 & .05 & .3592 & .66 \\
\hline $\begin{array}{l}\text { Inhalant abuse during } \\
\text { treatment }\end{array}$ & .5225 & .2648 & 3.8938 & .05 & 1.686 & 4.37 \\
\hline Unemployment & .7361 & .3983 & 3.4162 & .06 & 2.088 & 8.50 \\
\hline Scared as a trigger & 1.0832 & .0632 & 3.2247 & .07 & .3385 & .33 \\
\hline Respiratory infection & $\square 5697$ & .3224 & 3.1222 & .07 & .5657 & 2.72 \\
\hline Not motivated in treatment & .7035 & .3168 & 4.9317 & .03 & .4949 & .90 \\
\hline Mother substance abuse & .6055 & .2927 & 4.2799 & .04 & 1.832 & 3.36 \\
\hline $\begin{array}{l}\text { Hospitalization during } \\
\text { treatment }\end{array}$ & .7191 & .2876 & 6.2497 & .01 & 2.053 & 4.81 \\
\hline Taught by sibling & $\square 1.1757$ & .6704 & 3.0757 & .08 & .3086 & 2.00 \\
\hline
\end{tabular}


follow-up. Thus, variables with a positive relationship with the dependent variable (i.e., relapse) are associated with an increased probability of relapse during follow-up.

Table 4 shows that the strongest bivariate predictors of a relapse are hospitalization during treatment, drug abuse as a presenting problem at admission, the use of inhalants during treatment and lack of motivation during treatment. If a youth experienced the highest score on any of these variables, the probability of relapsing was increased. The odds ratio of each of these variables are included.

While abstinence during treatment was a predictor of relapse, it did not predict all relapses after treatment. Fifty-six young people used inhalants during the follow-up period compared with 22 who did not. That is, 71.8 percent of the young people tracked during follow-up for whom data was available relapsed after discharge. Of these, 17 were abstinent in treatment compared with 12 who were both abstinent before and after treatment $\left(?^{2}(1, \mathrm{~N}=78)=5.62, p<.05\right)$. Thus, the odds of not relapsing after treatment were 1.42:1 if the young person was abstinent during treatment. Similarly, young people who remained abstinent during treatment had a 58.62 percent chance of remaining abstinent during follow-up. These odds and probabilities might be different if a more stringent definition of "abstinence" was used. Similarly, motivation during treatment decreased the probability of relapse during follow-up.

Young people who used inhalants immediately before treatment and those who used inhalants during treatment had the largest odds of relapsing during follow-up. Thus, young people who used inhalants immediately before admission had 4.87:1 odds of relapsing while young people who abused inhalants during treatment had 4.37:1 odds of relapsing during follow-up.

Family support upon discharge decreased the probability and the odds of relapsing. Unfortunately, missing data concerning family support prevented its use in the multivariate model. However, we can speculate that having family support in place at discharge is an important ingredient of treatment that should be examined more closely in treatment programs and in future research.

Family history of substance abuse also seems predictive of further relapse, especially maternal substance abuse. Substance abuse by family members interferes with family at discharge since a family cannot be supportive of abstinence if family members abuse substances them- 
selves. Maternal substance abuse, again, can be a critical focus of treatment, since addiction, according to several theories, is a family problem. Mothers, often the primary caretakers, exert a strong influence on child development and behavior such that maternal substance abuse negatively influences their children.

\section{Multivariate Results}

The hierarchical logistic regression analysis on relapse as outcome included three predictors in the multivariate model: motivation, hospitalization, and inhalant use at admission. Seventy-eight young people were available for analysis.

Table 5 shows three predictor variables that are significantly related to relapse. Thus, motivation, as judged by staff during treatment, decreased the likelihood that a young person would relapse to inhalant use during follow-up. Conversely, the absence of motivation during treatment increased the probability that a young person would relapse after treatment. The remaining variable, hospitalization during treatment, also increased the probability that a young person would relapse after treatment. The classification table for this multivariate model showed that this multivariate model correctly predicted 74.67 percent of the cases.

Further information can be obtained through calculations of the data on Table 5. For example, the probability of a young person experiencing a relapse during follow-up can be computed using the Constant term and the coefficients displayed from the table. Thus, Equation 1 can be calculated as follows:

TABLE 5. Multivariate Logistic Regression: Variables that Successfully Predicted Inhalant Abuse at Follow-Up

\begin{tabular}{lrrrrr}
\hline Variable & $\square$ & S.E. & Wald & $\underline{p}$ & Exp (口) \\
\hline Current inhalant use & .6163 & .3167 & 3.785 & .05 & 1.852 \\
Motivated in treatment & $\square 1.102$ & 4087 & 7.271 & .007 & .3322 \\
Hospitalization & .7569 & .3625 & 4.359 & .04 & 2.132 \\
Constant & .4270 & .3632 & 1.382 & .24 & \\
\hline
\end{tabular}

Beginning $\square ?$ Log Likelihood 88.94 Ending $\square \gtrless$ Log Likelihood 70.87

Model Chi-Square 18.07, $p=.0004$ 


$$
P(\text { Event }=\text { Relapse })=\operatorname{Exp}(.4270+D) / 1+\operatorname{Exp}(.4270+D)
$$

In this equation, $D$ represents the linear relationship of the independent variables included in the model:

$D=$ Current inhalant use $(.6163)+$ Not motivated during treatment (1.102) + Hospitalization during treatment (.4270)

In the instance of a young person who has the most extreme scores for each measure, an individual with the highest risk profile as defined in this study would be one with the highest risk of relapsing with the following characteristics on the variables included in the model:

- Used inhalants immediately prior to admission;

- Was not motivated in treatment; and,

- Was hospitalized during treatment.

A young person with this profile experienced a .6678 probability of relapsing during follow-up based on the follow-up information.

The Model Chi-square and the changes in $\square \mathcal{R}$ Log Likelihood are statistics that help determine how well the model "fits" the data. A test of the full model with all three predictors against a Constant-only model was statistically reliable. In Table 5, the Model Chi-square was significant $(p=.0004)$ at 18.07 , showing the individual ratios were significantly different from 1.0 (no association) and that the two odds ratios were different from one another. In addition, the beginning $\square \mathcal{R}$ Log Likelihood was 88.94, dropping to 70.87 in the final model, revealing a robust drop. Therefore, the predictors, as a set, reliably discriminated between young people who relapsed during follow-up and those who did not.

\section{DISCUSSION}

This study describes the profile of a large number of young people admitted to a national treatment program for inhalant abuse. Data on seventy-eight young people from across Canada were collected from treatment files. All of the young people were Status Indian, admitted with the presenting problem of inhalant abuse. Nevertheless, the young people in this study also experienced a great number of other problems both at family and community levels. 


\section{Strengths and Limitations}

As mentioned previously, this study was retrospective and exploratory. It was also based on a secondary analysis of case files. A number of limitations are associated with these approaches such as data that was not designed for the purposes of this study and potential problems about reliability of coding. Further, there were missing data for some of the variables used in this study. However, given the exploratory nature of the study and the usefulness of the information, even with missing data, this paper serves as a preliminary investigation of the profiles of young people who received treatment for inhalant use. It also provides preliminary data about relapse after intervention.

Demographic data were entered to build a model to predict relapse to inhalant use during follow-up. Predictor variables, collected from the case files, were tested at the bivariate level against relapse of inhalant abuse. Because of the exploratory nature of the study, statistical significance was set at $p<.05$. Variables were entered simultaneously using the forced entry method to build the most parsimonious logistic regression model.

Follow-up information revealed that 56 out of 78 young people used inhalants after discharge. Follow-up workers were aware of only twenty-two young people who abstained from inhalant abuse during follow-up. Thirty-one other young people were lost to follow-up and were excluded from this study. Bivariate and multivariate logistic regression models were created to determine what variables successfully predicted relapse to inhalant abuse during follow-up. Two multivariate models were created.

The multivariate model included: motivation while in treatment, hospitalization, and use of inhalants immediately prior to admission to the treatment center. Thus, young people having the greatest risk of relapsing after treatment were those that were not motivated in treatment, who were hospitalized during treatment and who used inhalants immediately before being admitted to the treatment center. The multivariate model described in this paper fits this particular sample quite well. Hospitalization in treatment was a risk factor in relapse for a couple of reasons. The young people who were hospitalized during treatment were typically those with chronic health problems, most often related to inhalant use. They were also often the ones who 
continued to use solvents while in treatment and suffered physical problems as a result.

However, there is no guarantee that the same models would be built for another sample. Clearly, more research into inhalant abuse with other populations is needed. Inhalant abuse needs more research attention. This study offers a preliminary look at factors related to inhalant abuse. The highest risk factors in this study were most related to young person's lack of "readiness for change" (Prochaska \& DiClemente, 1982). Treatment programs must closely attend to the stage of change which clients are in and address their readiness for intervention. Further prospective research will help pinpoint predictors of relapse with greater precision.

Prediction equations provide valuable information about the simultaneous effect of factors that affect relapse. Logistic regression equations offer a better understanding of which factors are associated with outcome than do independent variables examined separately. The multivariate logistic regression model built from the data in this study provided a "blueprint" of the types of young people that the National Breakthrough Inhalant Program was least successful with. It also raised important program questions about what workers and administrators can do to address the effect of these factors for the young people in treatment.

\section{REFERENCES}

Bach, P., \& Bornstein, P. (1981). A social learning rationale and suggestions for behavioral treatment with American Indian alcohol abusers. Addictive Behavior, 6, 75-81.

Beauvais, F. (1992). Attitudes about drugs and the drug use of Indian Youth. American Indian and Alaska Native Mental Health Research, 5 (1), 38-42.

Beauvais, F., \& LaBoueff, S. (1985). Drug and alcohol abuse intervention in American Indian communities. The International Journal of the Addictions, 20 (1), 139-171.

Beauvais, F., \& Segal, B. (1992). Drug use patterns among American Indian youth and Alaskan Native youth: Special rural populations. Drugs \& Society, 7, 77-95.

Castiglia, P. (1993). Inhalant addiction. Journal of Pediatric Health Care, 7, 89-91.

Charles, G., \& Coleman, H. (in press). Journal of Child and Youth Care: Special Edition, Voices of the people: Solvent abuse in First Nations Communities.

Gurnee, C., Vigil, D., Krill-Smith, S., \& Crowley, T. (1990). Substance abuse among American Indians in an urban treatment program. American Indian and Alaska Native Mental Health Research, 3 (3), 16-17.

Han, P., Hagel, J., Welty, T., Ross, R., Leonardson, G., \& Keckler, A. (1994). Cultural factors associated with health-risk behavior: The Cheyenne River Sioux. American Indian and Alaska Native Mental Health Research, 5 (3), 15-29. 
Howard, M., \& Jenson, J. (1999). Inhalant use among antisocial youth: Prevalence and correlates. Addictive Behaviors, 24 (1), 59-74.

Innes, M., \& Charles, G. (1996). Inhalant abuse: Finding answers from within. Calgary, AB: Woods's Homes.

Johnson, D. (1994). Stress, depression, substance abuse, and racism. American Indian and Alaska Native Mental Health Research, 6 (1), 29-33.

Kandel, D., \& Logan, J. (1984). Patterns of drug use from adolescence to young adulthood: I. Periods of risk for initiation, continued use, and discontinuation. American Journal of Public Health, 74 (7), 660-665.

Mail, P., \& Johnson, S. (1993). Boozing, sniffing, and toking: An overview of the past, present, and future of substance abuse by American Indians. American Indian and Alaska Mental Health Research, 5 (2), 1-33.

Morgan, P., \& Teachman, J. (1988). Logistic regression: Description, examples and comparisons. Journal of Marriage and the Family, 50, 929-936.

Norusis, M. (1990). SPSS/PC + Advanced Statistics. Chicago, IL: SPSS Inc.

Prochaska, J., \& DiClemente, C. (1982). Transtheoretical therapy: Toward a more integrative model of change. Psychotherapy: Theory, Research and Practice, 19 (3), 276-288.

Schinke, S., Gilchrist, L., Schilling, R., Walker, D., Locklear, V., Bobo, J., Maxwell, J., Trimble, J., \& Cvetkovich, G. (1986). Preventing substance abuse among American Indian Native youth: Research issues and strategies. Journal of Public Service Research, 9 (4), 53-67.

Schinke, S., Orlandi, M., Schilling, R., Gilchrist, L., \& Landers, C. (1990). Tobacco use by American Indian and Alaska Native people: Risks, psychosocial factors, and preventive intervention. Journal of Alcohol and Drug Education, 35 (2), 1-12.

Schinke, S., Schilling, R., Gilchrist, L., Barth, R., Bobo, J., Trimble, J., \& Cvetkovich, G. (1985). Preventing substance abuse with American Indian Youth. Social Casework, 66, 213-217.

Sharpe, C. (1992). Introduction to inhalant abuse: A valuable research agenda. (National Institute on Drug Abuse Research monograph series), 129, 1-11.

Smart, R. (1997). Inhalant abuse in Canada. Substance Use \& Misuse, 32 (12 \& 13), 1835-1840.

Sverson, H. (1984). Adolescent social drug use: School prevention program. School Psychology Review, 13 (2), 150-161.

Tabachniak, B., \& Fidell, L. (1996). Using Multivariate statistics. New York: HarperCollins.

Yamaguchi, K., \& Kandel, D. (1984a). Patterns of drug use from adolescence to young adulthood: II. Sequence of progression. American Journal of Public Health, 74 (7), 668-671.

Yamaguchi, K., \& Kandel, D. (1984b). Patterns of drug use from adolescence to young adulthood: III. Predictors of progression. American Journal of Public Health, 74 (7), 673-681.

Zebrowski, P., \& Gregory, R. (1996). Inhalant use patterns among Eskimo School Children in Western Alaska. Journal of Addictive Diseases, 15 (3), 67-77. 